(Krasnoyarsk) were examined, of them 1348 boys and 1602 girls. The Chen Internet Addiction Scale (CIAS) with a cut-off level of 65 points was used. Internet users are divided into three groups: Adaptive Internet Users (AIU) (27-42 points); maladaptive Internet users (MIU) (43-64 points); pathological Internet users (PIU) (score $\geq 65$ ). Results: The AIU group comprised $50.3 \%$ (55.9\% boys and $45.6 \%$ girls, $\mathrm{p}<0.001)$. The share of adolescents aged $11-14$ is $52.0 \%$, the share of adolescents aged $15-18$ is $48.4 \%(\mathrm{p}=0.04)$. The MIU group constituted $42.9 \%$ ( $46.3 \%$ were girls and $38.9 \%$ boys, $\mathrm{p}<0.001)$. The share of adolescents aged $11-14$ is $42.1 \%$, and those aged $15-18$ is $43.8 \%, \mathrm{p}>0.05$. The PIU group constituted $6.8 \%$ (5.1\% boys and $8.2 \%$ girls, $\mathrm{p}<0.001)$. The share of adolescents aged $11-14$ is $5.9 \%$ and those aged $15-18$ is $7.8 \%(\mathrm{p}=0.04)$.

Conclusions: Among adolescents in Central Siberia the prevalence of AIU consist 50.3\%, MIU 42.9\%, PIU 6.8\%. The prevalence of PIU is more common in girls. The increase in PIU was marked in the older age group. The study was funded by RFBR project № 18-29-2203218. Conflict of interest: The reported study was funded by RFBR project № 18-29-22032\18.

Keywords: Internet; Addiction; prevalence; Siberia

\section{Ethics and psychiatry}

\section{EPP0669}

Manual and mechanical restraint and the hierarchy of coercive measures: Evidence or tradition?

M. Lynge ${ }^{1 \star}$, S. Dixen ${ }^{1}$, K. Johansen ${ }^{2}$, S. Düring ${ }^{2}$, A. Parnas ${ }^{3}$ and J. Nordgaard ${ }^{4}$

${ }^{1}$ Mental Health Center Amager, Mental Health Services in the Capital Region of Denmark, Copenhagen S, Denmark; ${ }^{2}$ Competence Centre For Dual Diagnosis, Mental Health Services in the Capital Region of Denmark, Roskilde, Denmark; ${ }^{3}$ Mental Health Center Glostrup,

Mental Health Services in the Capital Region of Denmark,

Copenhagen V, Denmark and ${ }^{4}$ Mental Health Center Amager, Mental Health Services in the Capital Region of Denmark, Copenhagen V,

Denmark

${ }^{\star}$ Corresponding author.

doi: 10.1192/j.eurpsy.2021.997

Introduction: In the continuous work to reduce the use of coercion in the psychiatric care, attention in Denmark has especially been directed towards mechanical restraint, i.e. the use of belts to fixate patients to a bed. While the use of mechanical restraint is currently decreasing, increases in other types of coercive acts are observed (e.g., forced medication and hourly episodes of manual restraint). The use of manual restraint refers to mental health workers immobilizing a patient to avoid harm to self or others. Manual restraint is generally considered less intrusive to a patient's autonomy than the use of mechanical restraint. However, no study has yet explored if it is actually experienced as such by the patients.

Objectives: This study explores patients' perspectives on manual and mechanical restraint, respectively.

Methods: We are currently performing a qualitative interview study of 10 patients, who have been exposed to both types of coercion. The interviews will be transcribed verbatim and analysed for thematic content.

Results: We expect to discover more nuanced perspectives of the intrusiveness of the different forms of coercion-perspectives that may challenge the assumption that one type of coercion is by default better than another. The study's results will be presented.

Conclusions: In this study, we only look at two types of coercion. More investigation into the differentiation of patients and ideal type of coercive measure is paramount to the ambitions of a better and more humanistic psychiatric care.

Keywords: Mechanical restraint; Patient experiences; coercion; Manual restraint

\section{EPP0670}

The position of the polish bishops' conference on LGBT+ - philosophical, theological, clinical and political aspects

\section{W. Kosmowski}

Department Of Psychiatry, Collegium Medicum, Nicolaus Copernicus University, Bydgoszcz, Poland doi: 10.1192/j.eurpsy.2021.998

Introduction: Practicing medicine cannot disregard cultural conditions. Philosophy and religion are elements of culture. For several years in Poland, various circles have discussed the extensive LGBT issues. A document of Polish Bishops on this subject appeared on 28.08.2020. In $2018,91.8 \%$ of people over 16 years old in Poland declared affiliation to the Roman Catholic Church (Statistics Poland 2020).

Objectives: The aim of the study is to present different perspectives of effects of that publication, including ethical evaluation and references to clinical practice.

Methods: Statements of protagonists and antagonists of this document in Polish were analyzed. Collected arguments were divided into types: philosophical - by philosophy branches (e.g. ethics, philosophical anthropology), theological and clinical.

Results: As of 29.09.2020 - 85,200 results in the Google Search after typing (in Polish) "Polish Episcopal Conference LGBT". The use of philosophical arguments by both parties results from the adaptation of different systems, e.g. regarding philosophical anthropology, some assume the immutability of human nature, others - its variability and susceptibility to shaping, e.g. human sexuality. Some emphasize the importance of non-discrimination, while others indicate the need to consider human essence in determining directions of actions.

Conclusions: Professionals should help everyone, regardless of conditions, in accordance with conscience and contemporary medical knowledge [Polish Code of Medical Ethics]. They should try to understand patients and the context of symptoms. Familiarizing oneself with arguments of both sides helps in this. But polemical language makes dialogue difficult. What for one is a "venerable tradition", for another is a "stereotype" or "discrimination".

Keywords: theology; sexual medicine; ethics

\section{EPP0671}

\section{Perception of otherness - the role of personality and demographic variables}

M. Preiss ${ }^{1,2 *}$, N. Doubková ${ }^{1}$ and J. Jonášs ${ }^{1,2}$

${ }^{1}$ Psychology, University of New York in Prague, Praha, Czech Republic and ${ }^{2}$ Psychology, National Institute of Mental Health, Klecany, Czech Republic

${ }^{*}$ Corresponding author.

doi: 10.1192/j.eurpsy.2021.999 
Introduction: The idea that personality can influence our perception of 'otherness' is widely accepted within the literature of social sciences. Undoubtedly, the principle of dehumanization played an important role in genocides during the $20^{\text {th }}$ and $21^{\text {st }}$ centuries. In totalitarian or post-totalitarian regimes 'otherness' may present a challenge to the absolute power. Recent studies showed that negative attitudes toward 'otherness' - also known as xenophobia - are on a rise in the Czech Republic.A deeper analysis of the personality in relation with perception of otherness is still missing.

Objectives: The presentation analyse the personality variables associated with the perception of otherness and compare the differences between various age groups, genders, individuals with different levels of education, and above all, the differences between various groups. Several contrast groups are compared - general population, high neuroticism sample, personality disorder sample, xenophobic and xenophilic sample.

Methods: Bogardus Scale of Social Distance as a measure of perception of otherness is compared with in-depth analysis of personality functioning (Semi-Structured Interview for Personality Functioning DSM-5, STiP-5.1).

Results: We analyze the results of five samples with respect to demographic variables, variables of personality functioning and try to point out the relationship between more attitudes and underlying personality functioning. The importance of some demographic variables (as age) and connections between personality functioning (Self and Interpersonal) and social distance is emphasized and discussed. Conclusions: The project help us to understand perception of otherness in light of demographic and relative power of personality factors.

Keywords: otherness; personality functioning; social distance

\section{EPP0672}

Limitation of therapeutic effort in pychiatric patients. about a case.

C. Martín Villarroel ${ }^{\star}$, L. Carpio Garcia, J. Dominguez Cutanda, G. Belmonte García, J. Matsuura, M. Sánchez Revuelta, M. Fernández-Torija Daza and E. García

Psiquiatría, Complejo Hospitalario Universitario de Toledo, Toledo, Spain

${ }^{*}$ Corresponding author.

doi: 10.1192/j.eurpsy.2021.1000

Introduction: Thanks to advances in medicine, more diseases are being cured, but this benefit can become a problem when it causes a worsening of quality of life.

Objectives: The objective of this paper is to analyze, regarding the following case, the convenience of treating or to limit the therapeutic effort (LTE) in psychiatric patients who are in situations at the end of life.

Methods: 62-year-old woman begins with depressive symptoms from financial problems. In 4 months ago she makes four suicide attempts (drug overdose, cuts, self-stabbing, and precipitation), being hospitalized in ICU after latter because of multiple trauma and shock. During that time, she had a bad evolution with several complications that made LTE be evaluated. A bibliographic search was performed from different database (Pubmed, TripDatabase) about LTE and ethical implications.

Results: Trying to prolong life by disproportionate means in a patient with a poor prognosis or poor quality of life is bad practice. We must assess the severity, quality of life, capacity and preferences of the patient to decide to treat or not, thus guaranteeing the principle of beneficence. It is also important to respect the principle of autonomy, accepting patients can refuse treatment. All this is equally applicable to psychiatric patients, whom we should not stigmatize but rather evaluate their ability to decide, as in any person.

Conclusions: In conclusion, in situations of high suffering and near death, it is necessary a complete evaluation of the patient (psychiatric or not) is carried out in order to act in the most ethical way.

Keywords: autonomy; limit the therapeutic effort; ethical; quality of life

\section{EPP0673}

\section{The right to die: Perspectives of mental health professionals in malta}

\section{G.J. Ellul}

Mental Health Department, Mount Carmel Hospital, Attard, Malta doi: 10.1192/j.eurpsy.2021.1001

Introduction: In their professional work, mental health professionals are continually working with individuals in distress, who may express a wish to end their lives.

Objectives: To understand the perspectives of mental health professionals towards a person's right to die.

Methods: A mixed-method technique was used: Stage 1 involved a validated online questionnaire sent to all professionals working within the public mental health services in Malta. Stage 2 consisted of a multidisciplinary discussion between six professionals asked to hypothetically manage a terminally ill patient requesting physicianassisted suicide. Thematic analysis was subsequently applied.

Results: The majority of mental health professionals disagreed with allowing a person to commit suicide, even in situations of crippling debt, overwhelming despair and family dishonour. Terminal illness elicited a varied response (Figure 1)

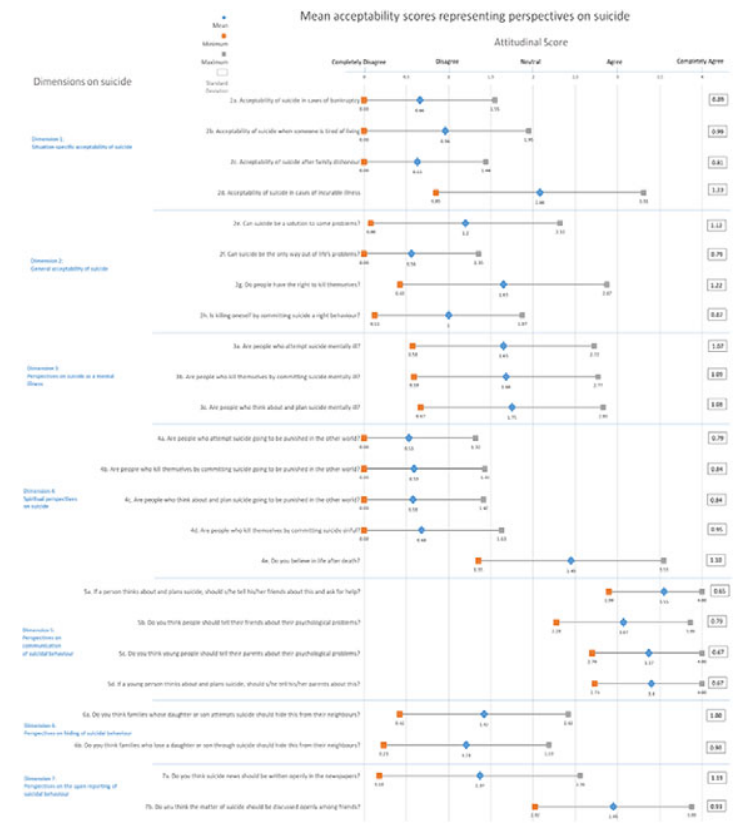

